\title{
Japanese Surveillance of Neuroendovascular Therapy in JR-NET - Part II. Japanese Registry of NeuroEndovascular Treatment 3. Main Report
}

\author{
Nobuyuki SAKAI, ${ }^{1}$ Kazutaka UCHIDA, ${ }^{2}$ Koji IIHARA, ${ }^{3}$ Tetsu SATOW, ${ }^{4}$ \\ Masayuki EzURA, ${ }^{5}$ Akio HyODO, ${ }^{6}$ Shigeru MiYACHI, ${ }^{7}$ Susumu MiYAMOTO, ${ }^{8}$ \\ Yoji NAGAI, ${ }^{9}$ Kunihiro Nishimura, ${ }^{10}$ Kazunori TOYODA, ${ }^{11}$ Shinichi YoshIMURA, ${ }^{2}$ \\ Hirotoshi IMAMURA, ${ }^{1}$ Chiaki SAKAI, ${ }^{2}$ Yuji MATSUMARU, ${ }^{12}$ and \\ Japanese Registry of Neuroendovascular Therapy (JR-NET) investigators
}

${ }^{1}$ Department of Neurosurgery, Kobe City Medical Center General Hospital, Kobe, Hyogo, Japan;

${ }^{2}$ Department of Neurosurgery, Hyogo College of Medicine, Nishinomiya, Hyogo, Japan;

${ }^{3}$ Department of Neurosurgery, Graduate School of Medical Sciences, Kyushu University, Fukuoka, Fukuoka, Japan;

${ }^{4}$ Department of Neurosurgery, National Cerebral and Cardiovascular Center, Suita, Osaka, Japan;

${ }^{5}$ Department of Neurosurgery, National Hospital Organization Sendai Medical Center, Sendai, Miyagi, Japan;

${ }^{6}$ Department of Neurosurgery, Dokkyo University Saitama Medical Center, Koshigaya, Saitama, Japan;

${ }^{7}$ Neuroendovascular Therapy Center, Aichi Medical University, Nagakute, Aichi, Japan;

${ }^{8}$ Department of Neurosurgery, Graduate School of Medicine, Kyoto University, Kyoto, Kyoto, Japan;

${ }^{9}$ Clinical and Translational Research Center, Kobe University Hospital, Kobe, Hyogo, Japan;

${ }^{10}$ Department of Preventive Medicine, National Cerebral and Cardiovascular Center, Suita, Osaka, Japan;

${ }^{11}$ Department of Cerebrovascular Medicine, National Cerebral and Cardiovascular Center, Suita, Osaka, Japan;

${ }^{12}$ Department of Neurosurgery, University of Tsukuba, Tsukuba, Ibaraki, Japan

\begin{abstract}
This study, following Japanese Registry of NeuroEndovascular Treatment 1 and 2 (JR-NET 1 \& 2), shows an annual trend of cases including adverse events and clinical outcomes at 30 days after NET. JR-NET3 was registered by 749 cumulative total number of physicians, certified by the Japanese Society of Neuroendovascular Therapy in 166 centers, between 2010 and 2014. Medical information about the patients was anonymized and retrospectively registered through a website. A total of 40,177 patients were recruited, 632 patients were excluded because data of preprocedural status were not available. So we analyzed 39,545 patients retrospectively. The proportion of octogenarians is increasing year-by-year and $14.7 \%$ in 2014 compared with $10.4 \%$ in 2010 . Most frequent target disease is intracranial aneurysm. For the proportion of the treatment of intracranial aneurysm, $50.0 \%$ in 2010 , but that has decreased to $44.8 \%$ in 2014 . However, number of procedures were increased from 3150 in 2010 to 3419 in 2014. Although before the positive clinical evidence of mechanical thrombectomy for acute ischemic stroke (AIS) was established, the proportion of endovascular treatment for AIS increased $13.8 \%$ in 2014 compared with $6.3 \%$ in 2010 . The number of patients requiring neuroendovascular treatment in Japan is increasing since 2010-2013, but that declined a little in 2014 caused by study operation suspended at the end of 2013. The outcomes of such therapy are clinically acceptable. Details of each type of treatment will be investigated in sub-analyses of the database.
\end{abstract}

Key words: nationwide surveillance, endovascular treatment, registry study, clinical outcome, safety endpoint

Received November 9, 2018; Accepted January 8, 2019

Copyright $@ 2019$ by The Japan Neurosurgical Society This work is licensed under a Creative Commons Attribution-NonCommercialNoDerivatives International License. 


\section{Introduction}

Recently, minimally invasive treatment is widely spreading, especially neuroendovascular therapy (NET) is progressing steadily due to advances in devices and increasing certified physicians in Japan. The Japanese Society of NET (JSNET) has certified physicians that consists of 1222 specialists, including 303 senior trainers on April 1, 2018, and it is an indispensable license to treat various cerebrovascular diseases such as cerebral aneurysm, supra-aortic artery stenosis/occlusion, arteriovenous shunts, and acute stroke. The Japanese Registry of NeuroEndovascular Treatment (JR-NET) study group endorsed by JSNET have been conducted an implemented retrospective studies [JR-NET 1 and 2 (JR-NET 1 \& 2) ${ }^{1)}$ to clarify the general status of NET delivered by JSNET-certified physicians. In this study (JR-NET 3), clinical and procedural data were retrospectively collected from January 2010 through December 2014. In 2015, it was a year of dramatically change at NET in Japan, because the usefulness of NET for acute ischemic stroke (AIS) was established, ${ }^{2-6)}$ and flow diverter ${ }^{7)}$ was approved for unruptured large or giant aneurysm of the internal carotid artery. However, this study's period was till 2014. The study aimed to determine annual changes in neuroendovascular treatment modalities and in major adverse events within 30 days in the same way as JR-NET 1 \& 2 .

\section{Materials and Methods}

\section{Study design}

JR-NET3 (2010-2014): This was the third nationwide surveillance of neuroendovascular treatments in Japan. The registry targeted all patients treated by JSNET board certified physicians between January 2010 and December 2014, except for those whom their physicians judged unsuitable for this registry. Medical information about the patients was anonymized and retrospectively registered through a website (https://jr-net.tri-kobe.net/jr-net/). Data were collected at the Translational Research Informatics Center (TRI, http://www.tri-kobe.org/). The study protocol, which is summarized briefly here, is available online with the full text of this article (https://www.jrnet.umin.jp/). All members of the writing committee assumed responsibility for the accuracy and completeness of the data and for the fidelity of the study with regard to the protocol.

\section{Patients}

All patients treated by neuroendovascular treatment at participating centers during the study period were basically enrolled in the study. The local institutional review boards at each institution approved the study protocol before the investigators proceeded with the study.

\section{Primary and secondary endpoints}

The primary endpoint was activities of daily life (ADL) determined according to Modified Rankin Scale (mRS) scores. ${ }^{8)}$ The secondary endpoints comprised the technical success of procedures and major adverse events that occurred within and at 30 days after procedures. A score of 0 on the mRS indicates no disability, whereas scores of 1 or 2 indicate slight disability (some help required with ADL but basically independent), scores of 3-5 indicate moderate disability (some help required with ADL) to severe disability (bedridden or constant specific care required), and a score of 6 indicates death.

Adverse events were classified as minor and major when $\mathrm{mRS}$ scores deteriorated by 1 and $\geq 2$ points, respectively. That are same in previous surveillance. ${ }^{11}$

\section{Statistical analysis}

Data were statistically analyzed using JMP 13 software (SAS Institute, Cary, NC, USA). The statistical significance of intergroup differences was assessed using the $t$-test for quantitative scales, Pearson's $\chi^{2}$ test; $P<0.05$ was considered as significant.

\section{Results}

\section{Backgrounds and characteristics of patients}

A total of 40,177 patients were recruited, 632 patients were excluded because data of preprocedural status were not available. So we analyzed 39,545 patients (mean age, $65.1 \pm 14.1$ years; female, $48.8 \%$ ) in this study (Table 1), which involved 749 cumulative total number of board-certified physicians at 166 centers in JR-NET3 (Appendix). Figure 1 shows the proportions of treated patients within various age groups. Although patients aged between 40 and 70 years were the main recipients of treatment, the rates of octogenarians increased annually from $10.4 \%$ in 2010 to $14.7 \%$ in 2014 $(P<0.001)$, whereas the ratio of younger patients ( $<40$ years) remained constant $(P=0.203)$. In the annual transition of the number of cases peaked in 2013 and declined in 2014.

\section{Procedures}

Among a total 39,545 procedure neuroendovascular procedures implemented between 2010 and 2014. The proportion of treatment for aneurysms were $46.1 \%$, angioplasty for carotid $22.5 \%$, angioplasty for others $10.5 \%$, embolization of brain and 
Table 1 Annual trends of JR-NET3 data

\begin{tabular}{|c|c|c|c|c|c|c|}
\hline & 2010 & 2011 & 2012 & 2013 & 2014 & Total \\
\hline Total number & $n=6794$ & $n=7292$ & $n=8348$ & $n=8924$ & $n=8095$ & $n=39,545$ \\
\hline Age & $64.8 \pm 14.0$ & $64.8 \pm 14.0$ & $65.3 \pm 14.0$ & $65.3 \pm 14.2$ & $65.8 \pm 14.2$ & $65.1 \pm 14.1$ \\
\hline Female & $3321(48.9 \%)$ & $3515(48.2 \%)$ & $4146(49.7 \%)$ & $4322(48.4 \%)$ & $3984(49.2 \%)$ & $19,288(48.8 \%)$ \\
\hline mRS before treatment & 0.46 & 0.46 & 0.50 & 0.48 & 0.48 & 0.48 \\
\hline Procedures & $n=6305$ & $n=6848$ & $n=7811$ & $n=8402$ & $n=7626$ & $n=36,992$ \\
\hline Aneurysm treatment & $3150(50.0 \%)$ & $3158(46.1 \%)$ & $3683(48.4 \%)$ & $3883(46.2 \%)$ & $3419(44.8 \%)$ & $17,293(46.7 \%)$ \\
\hline $\begin{array}{l}\text { Dome embolization, } \\
\text { ruptured }\end{array}$ & $1092(17.3 \%)$ & $1089(15.9 \%)$ & $1262(16.2 \%)$ & $1308(15.6 \%)$ & $1184(15.5 \%)$ & $5935(16.0 \%)$ \\
\hline $\begin{array}{l}\text { Dome embolization, } \\
\text { unruptured }\end{array}$ & $1811(28.7 \%)$ & $1840(26.9 \%)$ & $2181(27.9 \%)$ & $2279(27.1 \%)$ & $2009(26.3 \%)$ & $10,120(27.4 \%)$ \\
\hline $\begin{array}{l}\text { Dissection/parent } \\
\text { artery occlusion }\end{array}$ & $248(3.9 \%)$ & $229(3.3 \%)$ & $240(3.1 \%)$ & $296(3.5 \%)$ & $226(3.0 \%)$ & $1239(3.3 \%)$ \\
\hline Angioplasty/stenting & $1882(29.8 \%)$ & $2039(29.8 \%)$ & $2234(28.6 \%)$ & $2397(28.5 \%)$ & $2063(27.1 \%)$ & $10,615(28.7 \%)$ \\
\hline Carotid artery & $1518(24.1 \%)$ & $1605(23.4 \%)$ & $1775(22.7 \%)$ & $1948(23.2 \%)$ & $1655(21.7 \%)$ & $8501(23.0 \%)$ \\
\hline $\begin{array}{l}\text { Vertebral/subclavian } \\
\text { artery }\end{array}$ & $164(2.6 \%)$ & $198(2.9 \%)$ & $214(2.7 \%)$ & $197(2.3 \%)$ & $175(2.3 \%)$ & $948(2.6 \%)$ \\
\hline Intracranial artery & $200(3.2 \%)$ & $236(3.4 \%)$ & $245(3.1 \%)$ & $252(3.0 \%)$ & $233(3.1 \%)$ & $1166(3.2 \%)$ \\
\hline $\begin{array}{l}\text { Brain \& spinal AVM } \\
\text { embolization }\end{array}$ & $257(4.1 \%)$ & $241(3.5 \%)$ & $261(3.3 \%)$ & $294(3.5 \%)$ & $268(3.5 \%)$ & $1321(3.6 \%)$ \\
\hline DAVF embolization & $347(5.5 \%)$ & $415(6.1 \%)$ & $416(5.3 \%)$ & $493(5.9 \%)$ & $463(6.1 \%)$ & $2134(5.8 \%)$ \\
\hline Tumor embolization & $273(4.3 \%)$ & $321(4.7 \%)$ & $353(4.5 \%)$ & $422(5.0 \%)$ & $363(4.8 \%)$ & $1732(4.7 \%)$ \\
\hline $\begin{array}{l}\text { Acute stroke } \\
\text { treatment }\end{array}$ & $396(6.3 \%)$ & $674(9.8 \%)$ & $864(11.1 \%)$ & $913(10.9 \%)$ & $1050(13.8 \%)$ & $3897(10.5 \%)$ \\
\hline Physicians in charge & $n=6791$ & $n=7289$ & $n=8348$ & $n=8921$ & $n=8093$ & $n=39,442$ \\
\hline $\begin{array}{l}\text { Senior trainer, board } \\
\text { certified }\end{array}$ & $3689(54.3 \%)$ & $3862(53.0 \%)$ & $4311(51.6 \%)$ & $4738(53.1 \%)$ & $4226(52.2 \%)$ & $20,826(52.8 \%)$ \\
\hline $\begin{array}{l}\text { Specialist, board } \\
\text { certified }\end{array}$ & $2807(41.3 \%)$ & $3070(42.1 \%)$ & $3623(43.4 \%)$ & $3724(41.7 \%)$ & $3425(42.3 \%)$ & $16,649(42.2 \%)$ \\
\hline Non-specialist & $295(4.3 \%)$ & $357(4.9 \%)$ & $414(5.0 \%)$ & $459(5.1 \%)$ & $442(5.5 \%)$ & 1967 (5.0\%) \\
\hline
\end{tabular}

spinal arteriovenous malformations (AVMs), dural arteriovenous fistulae (dAVF) 8.9\%, and acute stroke $5.9 \%$ of procedures, respectively in 2010 . Thus, in 2014, the treatment for aneurysm was 42.5 , angioplasty for carotid $20.5 \%$, acute stroke $12.7 \%$, angioplasty for others $9.1 \%$, AVMs/dAVF 9.1\%, respectively. The proportion of treatments remained relatively constant, but acute stroke significantly increased from $5.9 \%$ in 2010 to $12.7 \%$ in 2014 $(P<0.001)$ (Fig. 2).

Elective or emergency procedures The rate of emergency treatment was increasing little-by-little between $32 \%$ and $36 \%$ throughout the study period (Fig. 3).

Physicians in-charge The proportion of treatment procedures with JSNET senior trainers, specialists, and non-specialist in charge $52.8 \%, 42.2 \%$, and $5 \%$, respectively remained relatively constant (Table 1 ).
mRS scores before and after treatment Figures $4 \mathrm{~A}$ and $4 \mathrm{~B}$ shows the overall proportions of mRS scores before and after treatment. Before treatment, $\geq 90 \%$ of patients were in relatively good condition, with mRS scores of $0-2$ (Fig. 4A). At 30 days after undergoing procedures, the patients maintained mRS scores of 0-2 decreased from $79.4 \%$ in 2010 to $76.3 \%$ in 2014 (Fig. 4B). mRS scores after each type of procedure Figure 5 shows the outcomes of each type of treatment according to $\mathrm{mRS}$ scores. Outcomes were favorable for $58.3 \%$ and $95.3 \%$ of patients with ruptured and unruptured aneurysms, respectively, (mRS 0-2) and for $\geq 85 \%$ those after carotid artery stenting (CAS), vertebral artery (VA)/subclavian artery (SCA), dAVF, and tumors. On the other hand, $75.5 \%, 71.6 \%$, and only $33.1 \%$ of those treated for intracranial artery disease, in AVM, and acute stroke had favorable outcomes. 


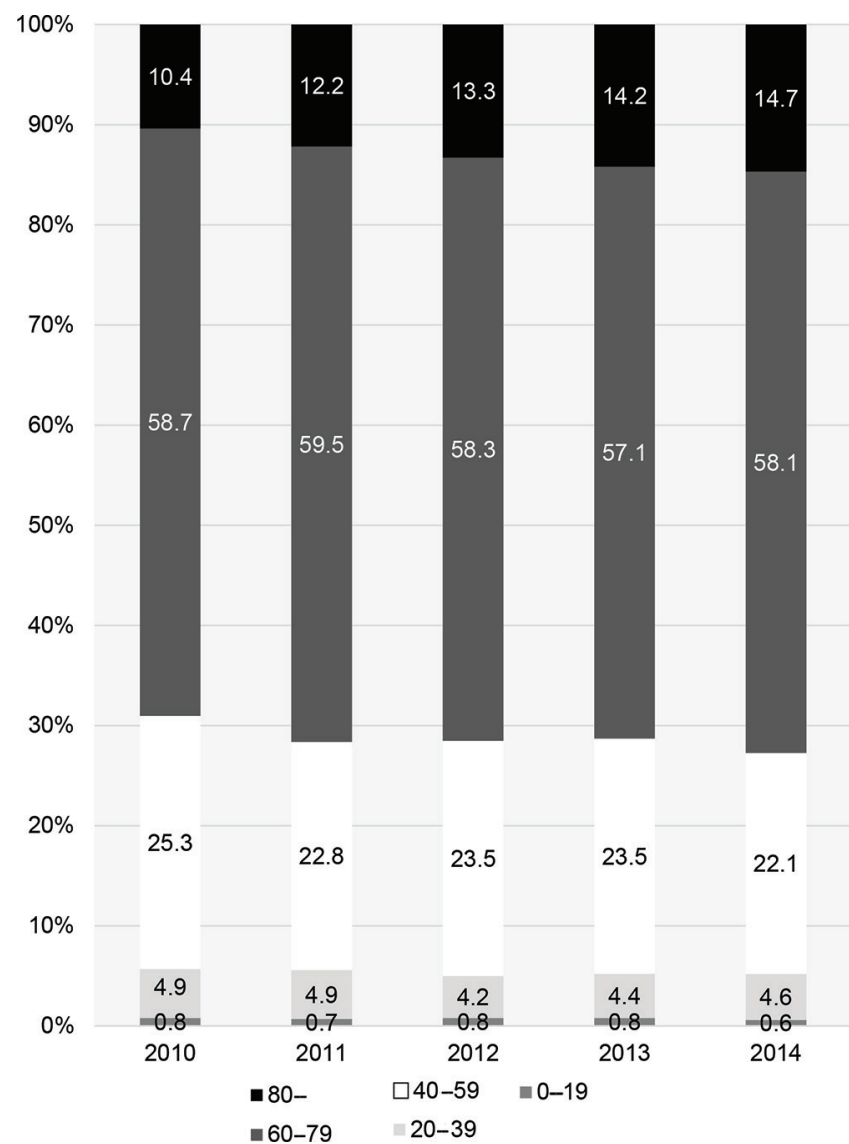

Fig. 1 Annual changes in patients' age during JR-NET3. Rates of octogenarians increased annually from $10.4 \%$ in 2010 to $14.7 \%$ in $2014(P<0.001)$, whereas the ratio of younger patients $(<40$ years $)$ remained constant $(P=0.203)$. JR-NET3: Japanese Registry of Neuroendovascular Therapy 3 .

Procedural complications of each treatment Figure 6 shows the frequency of procedural complications after each type of treatment. Death and major procedural complications occurred in $5.1 \%$ and $1.4 \%$ of patients treated for ruptured and unruptured aneurysms, respectively.

None of the patients died of procedure-related complications after VA/SCA, and tumors. Major complication and death occurred mostly in acute stroke and ruptured aneurysm which was about $5 \%$. In another procedures, the occurrence of death and major complication was around $1-2 \%$.

\section{Discussion}

This study, following JR-NET 1 \& 2, shows an annual trend of cases including adverse events and clinical outcomes at 30 days after neuroendvascular therapy. It has huge number of cases, about 40,000 cases, showing the actual state of neuroendovascular

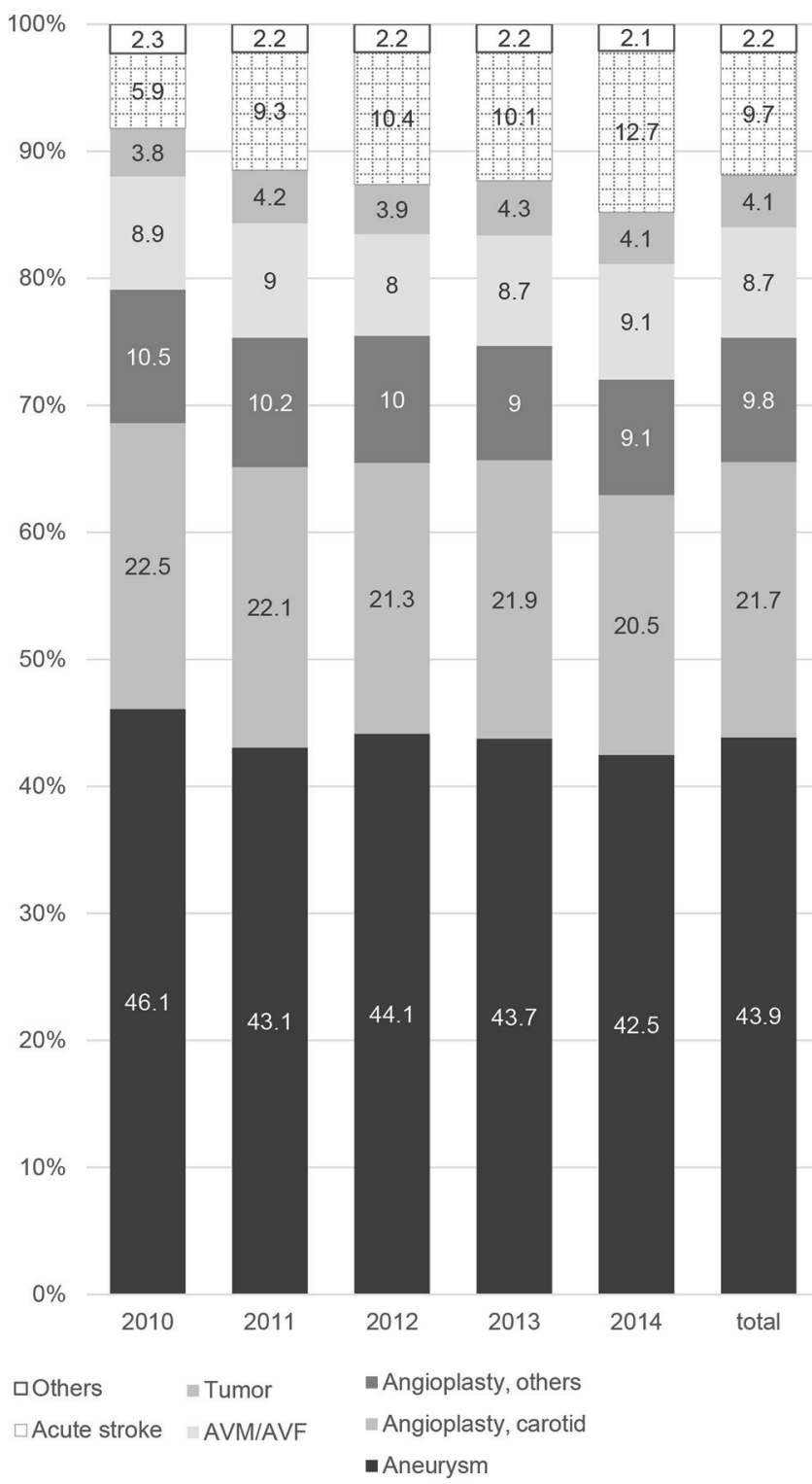

Fig. 2 Annual changes in the types of procedures. The proportion of treatments remained relatively constant, but acute stroke significantly increased from $5.9 \%$ in 2010 to $12.7 \%$ in $2014(P<0.001)$.

therapies in Japan. This study was conducted from 2010 to 2014. Many new devices, Merci V retriever (Stryker Neurovascular, Fremont, CA, USA) ${ }^{9,10)}$ and Enterprise VRD (Cerenovus, Johnson and Johnson, New Brunswick, NJ, USA) ${ }^{11)}$ in 2010, Penumbra system (Penumbra, Alameda, CA, USA) ${ }^{12)}$ in 2011, Neuroform EZ (Stryker Neurovascular) ${ }^{13)}$ in 2012, Wingspan stent system (Stryker Neurovascular) ${ }^{14}$ in 2013, Solitaire FR (Medtronic Neurovascular, Irvine, CA, USA) ${ }^{15)}$ and Trevo ProVue retriever (Stryker Neurovascular) $^{16)}$ in 2014 were started for reimbursement. Thus, it was the beginning of stents for intracranial aneurysm treatment, thrombectomy 


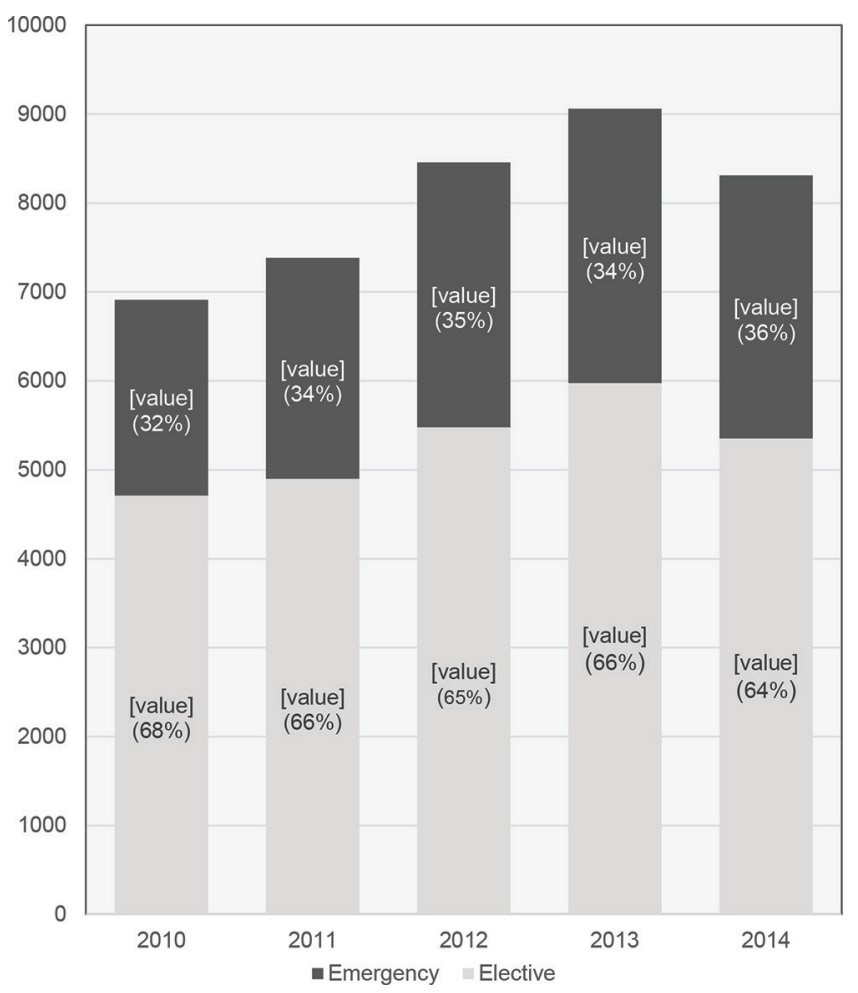

Fig. 3 Number of elective and emergency procedures. The total numbers of elective and emergency procedures increased annually except for 2014, and emergency procedure significantly increased from $31.9 \%$ in 2010 to $35.6 \%$ in $2014(P<0.001)$. and intracranial stent for ischemic stroke. But, it was before the positive clinical evidence of endovascular treatment for AIS was established, ${ }^{2-6)}$ and flow diverter stent ${ }^{7)}$ was reimbursed. Overall, the proportion of elderly people aged 80 or over has been increasing $14.7 \%$ in 2014, and it is doubled even compared with previous survey $7.0 \%$ in $2005{ }^{11}$ This might be caused by the increase in the population of elderly people and the fact that NET is less invasive, which is more likely to be applied to older people.

In the annual trend of the number of cases, it has been increasing steadily until 8402 in 2013, but declined to 7626 in 2014. In addition, emergency cases have been in the range of $32-36 \%$, which is about 5\% increase compared with JR-NET 1 \& 2 . This reflects suggested the increase in acute stroke. The mRS before NET was similar to JR-NET 1 \& 2, in which the ratio of mRS 0-2 was $93.3 \%$ from the previous $91.3 \%$, but the postoperative mRS deteriorated in which the ratio of mRS 0-2 was $77.2 \%$ from the previous $82.5 \%$. It suggested that the cause of the decrease in the percentage of independence after onset due to increase of acute stroke. In this study, the good prognosis of mRS 0-2 at 30 days after the procedure was 33.1\%. Endovascular therapy in ischemic stroke with acute large-vessel occlusion: Recovery by Endovascular Salvage for Cerebral UltraAcute Embolism Japan Registry 2 (RESCUE - Japan

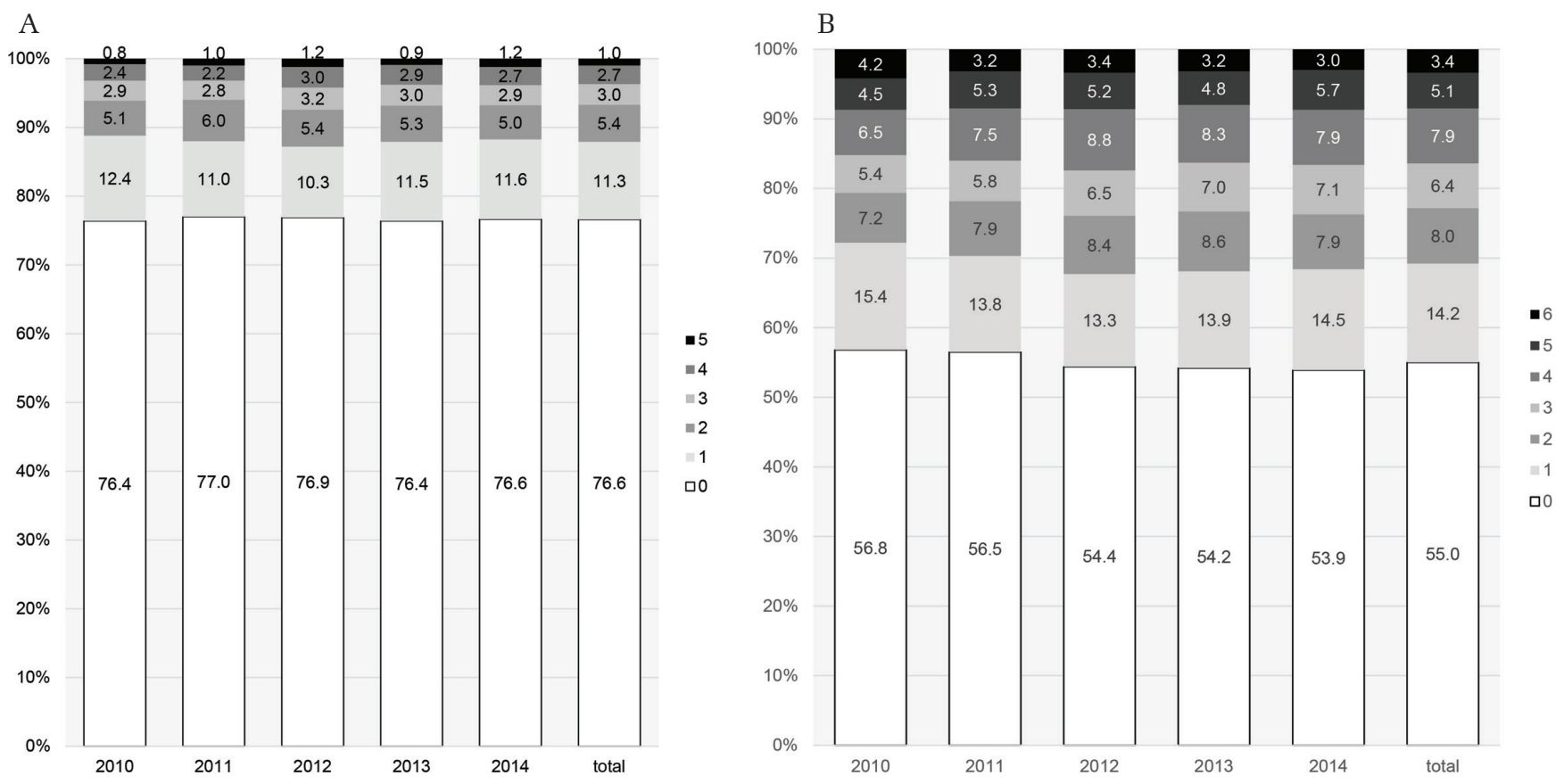

Fig. 4 Proportions of Modified Rankin Scale (mRS) scores before and after procedures. Ratio of patients with mRS 0-2 was $\geq 90 \%$ before therapeutic procedures (A), decreased at 30 days thereafter (B), but remained $>75 \%$. 


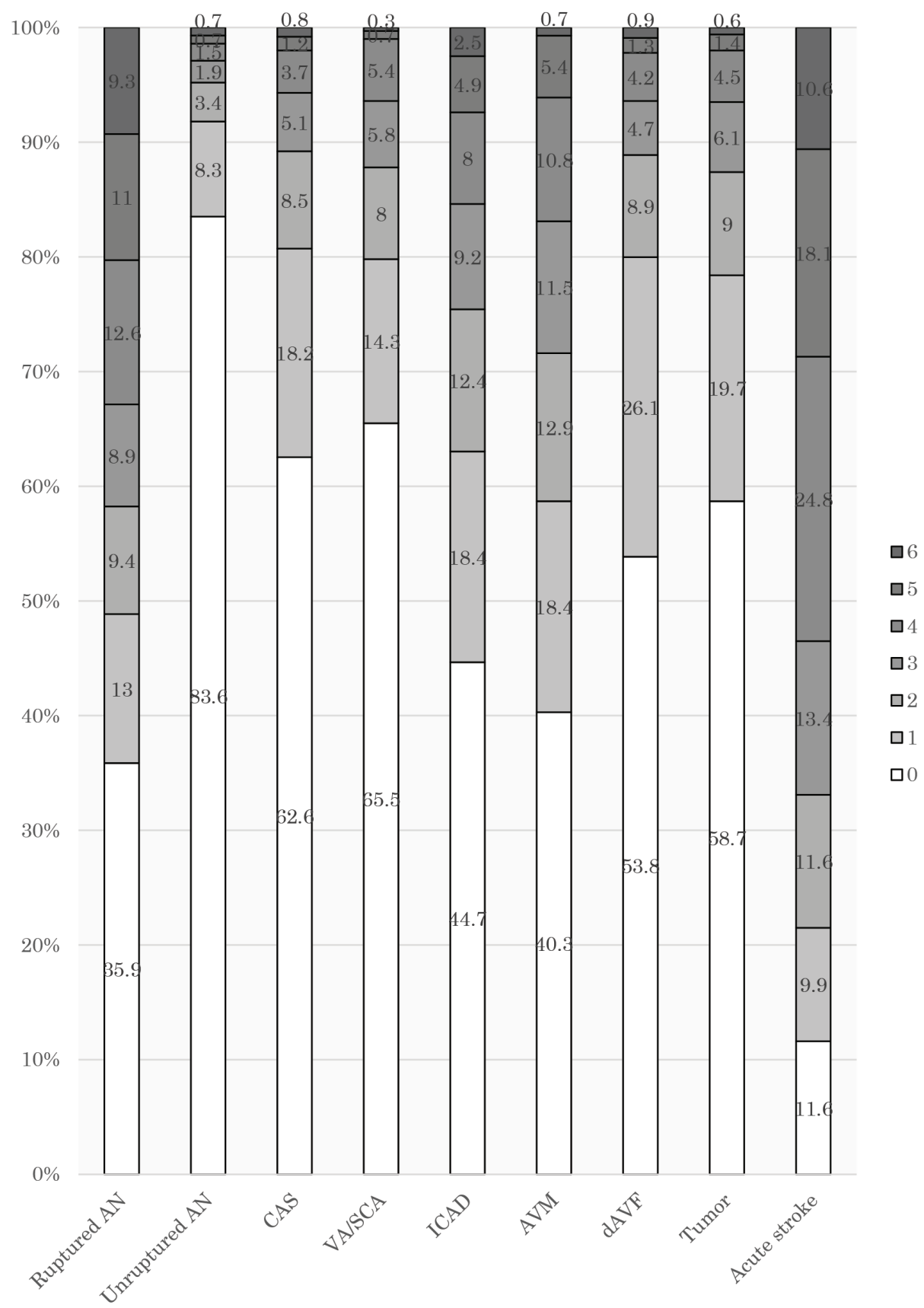

Fig. 5 Proportions of Modified Rankin Scale (mRS) scores at 30 days after various procedures. Outcomes were favorable (mRS 0-2) for $58.3 \%$ and $\mathbf{9 5 . 3} \%$ of patients with ruptured and unruptured aneurysms respectively. Ratios of favorable outcomes of carotid artery stenting, vertebral artery/subclavian artery, dural arteriovenous fistula, and tumor embolization were $>\mathbf{8 5} \%$. On the other hand, the ratios of favorable outcomes were $\mathbf{7 5 . 5 \%} \%$, $\mathbf{7 1 . 6} \%$, and only $33.1 \%$ in intracranial artery disease, arteriovenous malformation and acute stroke, respectively.

Registry 2) ${ }^{17)}$ showed mRS $0-2$ at 90 days after the procedure was $35.1 \%$. The results were similar of them. The minor complication overall increased to $3.5-9.4 \%$ compared with JR-NET 1 \& $2(0.7-2.2 \%)$, but the ratio of major complication $(0.5-3.7 \%)$ and death $(0-2.4 \%)$ has not increased compared with the ratio of major complication $(0-2.8 \%)$ and death $(0.6-5.8 \%)$ in JR-NET 1 \& 2 . The reason was suggested that asymptomatic, transient ischemia, and high intensity images in magnetic resonance image on diffusion waited image were firmly registered.

A nationwide population-based cohort study in Taiwan showed mortality of subarachnoid hemorrhage after neuroendocascular therapy was $10.4 \%$ similar 


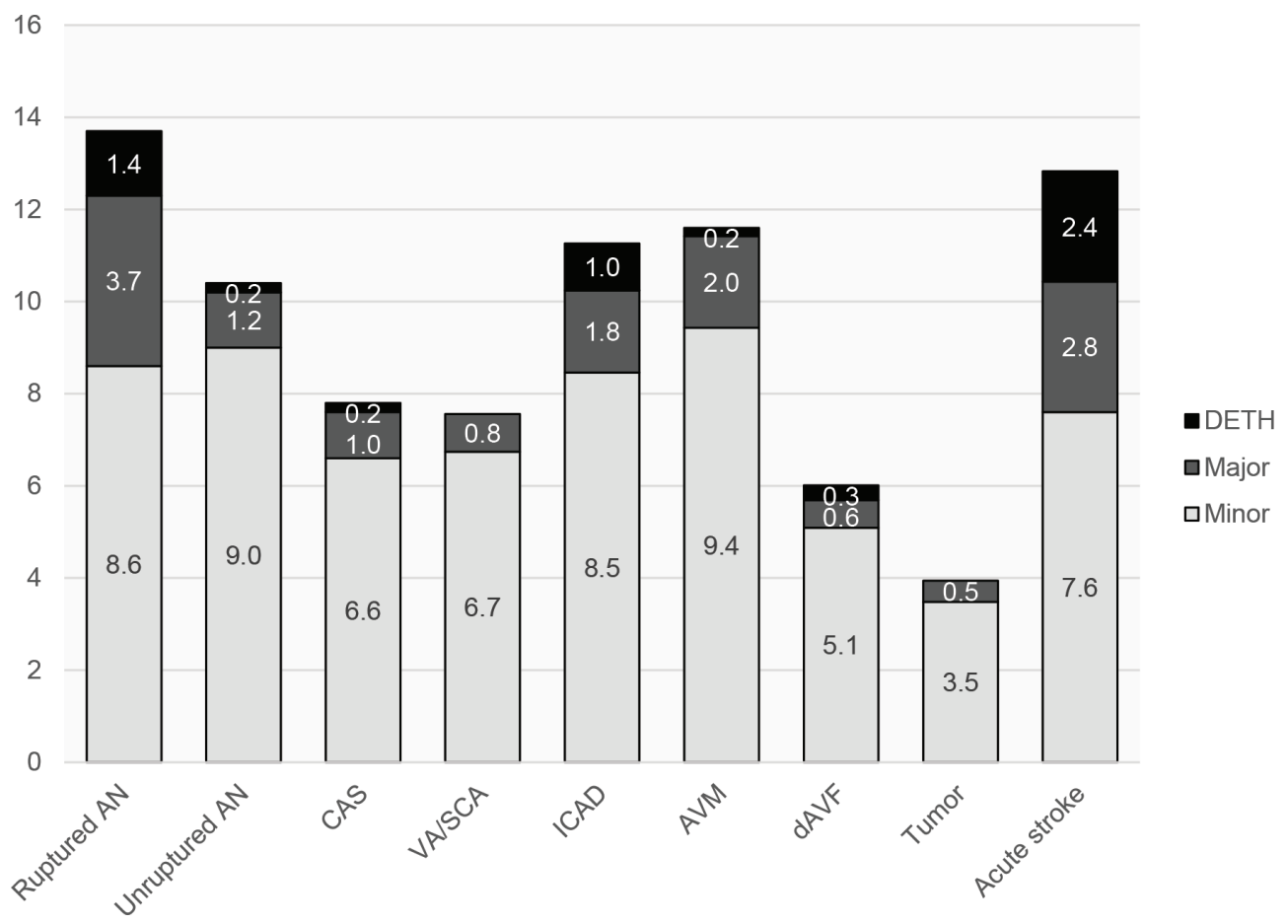

Fig. 6 Complications associated with each procedure. Death and major complication rates were higher after procedures for ruptured aneurysm $(5.1 \%)$ and acute stroke $(5.23 \%)$, but less frequent for those that treated dural arteriovenous fistula $(0.46 \%)$, tumor embolization $(0.46 \%)$, and vertebral artery/ subclavian artery $(0.82 \%)$. to $9.3 \%$ in this study suggesting identical result in Asian. ${ }^{18)}$ At 30-day follow-up, mortality after CAS performed by physicians with varied experience and utilizing a formal training program was $1.1 \%{ }^{19)}$ higher than $0.7 \%$ in our study $(P=0.09)$.

This study has some limitations. First, this study was retrospective study, and detailed data concerning individual patients were not obtained. Second, this study covered at about $40 \%$ of all procedures performed in Japan, and completeness of the survey was insufficient. Finally, this study was registered in Japan, and are consequently, of uncertain generalizability. For the future, JR-NET4 with higher completeness are considered necessary to more precisely clarify the status of NET in Japan.

\section{Conclusion}

This study showed NET was certain safety and effective in Japan. This study's period was before establishing the effectiveness of endovascular treatment for acute ischemic stroke in 2015. So it is expected that the number of cases will increase rapidly in the future. Details about each treatment or disease will be assessed in sub-analyses of this database.

\section{Acknowledgments}

The JR-NET3 Study Group: Co-principal investigator; Nobuyuki Sakai, Kobe City Medical Center General
Hospital, Kobe, Japan, Koji Iihara, Kyushu University, Fukuoka, Japan, Tetsu Satow, National Cerebral and Cardiovascular Center, Suita, Japan; Investigators; Masayuki Ezura, Sendai Medical Center, Sendai, Japan, Akio Hyodo, Dokkyo Medical University Saitama Medical Center, Koshigaya, Japan, Shigeru Miyachi, Aichi Medical University, Aichi, Japan, Susumu Miyamoto, Kyoto University, Kyoto, Japan, Yoji Nagai, Kobe University, Kobe, Japan, Kunihiro Nishimura, National Cerebral and Cardiovascular Center, Suita, Japan, Kazunori Toyoda, National Cerebral and Cardiovascular Center, Suita, Japan; Co-investigators; Toshiyuki Fujinaka, Osaka Medical Center, Osaka, Japan, Toshio Higashi, Fukuoka University, Fukuoka, Japan, Masaru Hirohata, Kurume University, Kurume, Japan, Japan, Akira Ishii, Kyoto University, Kyoto, Japan, Hirotoshi Imamura, Kobe City Medical Center General Hospital, Kobe, Japan, Yasushi Ito, Shinrakuen Hospital, Niigata, Japan, Naoya Kuwayama, Toyama University, Toyama, Japan, Hidenori Oishi, Juntendo University, Tokyo, Japan, Yuji Matsumaru, Tsukuba University, Tsukuba, Japan, Yasushi Matsumoto, Konan Hospital, Sendai, Japan, Ichiro Nakahara, Fujita Medical University, Aichi, Japan, Chiaki Sakai, Hyogo College of Medicine, Nishinomiya, Japan, Kenji Sugiu, Okayama University, Okayama, Japan, Tomoaki Terada, Showa University Fujigaoka Hospital, Kanagawa, Japan, Shinichi Yoshimura, Hyogo College of Medicine, Nishinomiya, Japan, and Certified Specialist of Japanese Society of Neuroendovascular Therapy. 


\section{Sources of Funding}

This study was supported in part by a Grant-inAid (Junkanki-Kaihatsu H24-4-3) from the National Cerebral and Cardiovascular Center, Japan and by Hatazaki Foundation, Kobe, Japan. The authors would like to express our gratitude to Ms. Hiroko Maruyama for helping preparation of manuscript.

\section{Conflicts of Interest Disclosure}

All authors who are members and non-members of the Japan Neurosurgical Society (JNS) have registered self-reported COI disclosure statements through the website for JNS. Nobuyuki Sakai; UNRELATED: Consultancy: Achieva, Cardiatis, Cerenovus/Johnson and Johnson, Medtronic, Microvention/Terumo, Penumbra, Stryker; Grants; Terumo (research grant). All co-authors have no conflict of interest for this manuscript.

\section{Appendix}

Participants, their hospitals, and the number of registered patients in JR-NET3 are listed when $>100$ patients were registered; names of investigators are listed when $<100$ patient were registered. N Sakai, $\mathrm{H}$ Adachi, Y Ueno, H Yamagami, H Imamura, $\mathrm{T}$ Kunieda, M Koyanagi, Y Kuramoto, K Todo, T Ishikawa, T Shigematsu, S Yamamoto, S Sato, K Asai, K Arimura, S Tani, Y Mineharu, O Narumi, A Ishii, C Sakai, H Ikeda, T Kono, Kobe City Medical Center General Hp.,1100; Y Matsumoto, R Kondo, E Furui, I Suzuki, T Takahashi, T Akiyama, H Endo, K Sato, Y Kageyama, S Ssawa, K Niizuma, Y Yazawa, R Itabashi, Konan Hp., 1086; M Ezura, N Kimura, K Tsuboi, K Sato, S Nishimura, K Sato, S Osawa, I Suzuki, Sendai Medical Center, 942; K Sugiu, Y Terai, K Tokunaga, A Katsumata, N Kusaka, A Nishida, S Kawada, K Watanabe, T Hishikawa, K Hirashita, H Itami, Okayama Univ., 917; S Ota, Y Sekihara, N Shimizu, K Maeda, Ota Memorial Hp., 900; Y Matsumaru, H Izumoto, W Tsuruta, Y Nakane, H Okumura, M Hayakawa, Y Hirota, M Sato, Y Kamiya, A Watanabe, T Amano, M Aoki, T Hyuga, D Watanabe, K Mori, M Seida, T Osanai, Toranomon Hp., 886; M Hirohata, M Takeuchi, Kurume Univ., 875; M Tsutsumi, K Nii, H Eto, K Kazekawa, H Aikawa, M Onizuka, H Yoshida, K Sakamoto, T Mizokami, H Oishi, M Iko, K Nakai, S Kin, Fukuoka Univ. Chikushi Hp., 785; T Nonaka, Y Yonemasu, A Takahashi, T Onda, S Kogure, R Ueda, T Shimizu, T Nomura, A Yamamura, S Hayashi, Shiroishi Memorial Hp., 751; I Nakahara, M Nakamura, S Furuichi, Y Iwamuro, T Ohta, S Toyota, E Furui, Y Watanabe,
S Matsumoto, R Ishibashi, Y Urabe, M Gomi, Y Fukushima, M Saka, T Nakazawa, Y Matsuda, Kokura Memorial Hp., 702; A Hyodo, Y Hori, M Shirato, K Suzuki, S Suzuki, T Takigawa, N Shimizu, Y Tanaka, I Takano, Dokkyo Medical Univ. Koshigaya Hp., 666; T Satow, K Iihara, T Okazaki, K Morita, H Yamagami, K Ito, S Sugata, M Hayakawa, T Matsushige, D Ishii, T Ishikawa, K Fukuda, K Masuda, T Hashimoto, Y Miyazaki, E Hamano, D Maruyama, N Nakajima, H Okumura, N Funatsu, National Cerebral and Cardiovascular Center, 666; S Yoshimura, J Kokuzawa, Y Enomoto, Y Yoshida, Y Egashira, $\mathrm{T}$ Takagi, K Yamada, M Ishiguro, $M$ Tsujimoto, H Watarai, K Yamauchi, H Kitajima, Gifu Univ., 644; H Ishihara, F Oka, T Oku, Yamaguchi Univ., 609; A Kumasaka, K Harada, J Morioka, Fukuoka Wajiro Hp., 601; I Hattori, M Morimoto, S Ozaki, S Kobanawa, M Sasaki, Y Matsumaru, Yokohama Shintoshi Neurosurgical Hp., 598; K Kawaguchi, M Kawanishi, A Shindo, N Hayashi, K Kawakita, T Yano, T Inukai, M Okauchi, Kagawa Univ., 513; T Kuroiwa, F Shimizu, M Shirakawa, H Oonishi, Shimizu Hp., 505; T Nakahara, K Yamashita, H Ohta, I Kamata, H Araki, R Ogami, Matsuda Hp., 488; T Hatano, A Ishii, H Hasegawa, T Kunieda, M Loyanagi, Y Yakenobu, K Yoshida, E Ogino, T Kikuchi, K Takemoto, N Yamana, M Goto, T Munemitsu, Y Yokoyama, H Chihara, Y Mineharu, M Ando, M Saiki, Y Sekihara, N Murai, Y Yamao, H Ikeda, H Hayashi, T Waro, S Sateshima, D Arai, N Sakai, Kyoto Univ., 487; M Nakamura, $\mathrm{T}$ Mizobe, Hyogo Brain and Heart Center, 484; S Miyachi, I Ikushima, T Izumi, N Matsubara, $\mathrm{K}$ Haraguchi, $\mathrm{T}$ Makiuchi, $\mathrm{K}$ Hashimoto, $\mathrm{T}$ Asai, Nagoya Univ., 478; T Hyogo, T Kataoka, T Ogino, H Endo, Nakamura Memorial Hp., 451; K Imai, $\mathrm{T}$ Takegami, M Hamanaka, T Yamada, Japanese Redcross Kyoto Daiichi Hp., 433; N Ikeda, Ube-Kohsan Central Hp., 396; T Okamoto, T Kano, H Toi, S Matsubara, Kawasaki Medical School Hp., 395; K Murao, K Nakazawa, A Takahashi, N Nakajima, Y Iwamuro, T Ohta, S Aketa, N Takabatake, T Kunieda, H Fukuda, K Takemoto, K Miyake, J Morioka, H Yukawa, T Akiyama, Shiroyama Hp., 383; H Konno, K Nakahara, M Nishio, H Hiramatsu, K Shibanai, Japanese Redcross Hachinohe Hp., 375; A Nishio, S Yamauchi, K Kondo, K Haraguchi, K Hayasaki, Y Mitsuhashi, T Kawakami, S Yamauchi, A Mizuguchi, K Demura, T Hishikawa, Hokuto Hp., 365; K Satoh, M Hanaoka, S Manabe, T Tamura, T Kinouchi, J Tsurukiri, Y Fukushima, Japanese Redcross Tokushima Hp., 365; N Horie, M Morikawa, K Hayashi, T Higashi, Y Morofuji, Nagasaki Univ., 364; Y Nakai, S Irie, W Tsuruta, T Takigawa, Y Matsumaru, M Sato, G Ikeda, Tsukuba Univ., 363; K Nakazawa, J Ayabe, Yokohama Kyosai Hp., 357; K Akaji, T Iwai, I Naito, 
T Dembo, R Ueda, H Ishimori, T Akiyama, T Kano, H Kimura, K Suzuki, Mihara Memorial Hp., 355; $\mathrm{T}$ Fujinaka, R Kajikawa, T Nishida, N Ohara, M Sakaguchi, H Nakamura, K Asai, Osaka Univ., 344; O Tone, K Shigeta, H Yatsushige, national Disaster Medical Center, 344; M Mohri, N Uchiyama, J Hamada, K Misaki, Kanazawa Univ., 341; N Toma, M Shibata, Y Sato, K Hayashi, T Nonaka, H Sakaida, Japanese Redcross Ise Hp., 339; J Satomi, M Hanaoka, S Manabe, T Tamura, J Tsurukiri, Y Fukushima, Tokushima Univ., 336; S Aketa, Osaka Police Hp., 327; K Fujimoto, Osaka General Medical Center, 324; H Morishima, H Ito, T Terada, T Wada, H Onodera, St. Marianna Medical Univ., 305; N Kuwayama, K Tsumura, S Nagao, Kawasaki Saiwai Hp., 304; Y Kiura, T Okazaki, S Sakamoto, Y Sahara, M Shibukawa, T Mitsuhara, K Shinagawa, K Hirashita, T Matsushige, D Ishii, Hiroshima Univ., 291; T Tsumoto, K Yasumori, T Uwatoko, Y Sambongi, S Tokunaga, Kyushu Medical Center, 288; N Toma, F Asakura, H Sakaida, T Sano, Y Umeda, Y Nakatsuka, A Yamamoto, Y Miura, M Saka, Mie Univ., 280; K Takayama, H Nakagawa, I Nakagawa, Y Shibata, T Wada, Nara Medical Univ., 277; K Nakahara, Takagi Hp., 274; I Naito, N Miyamoto, T Iwai, S Takatama, T Shimizu, S Tomizawa, K Wakabayashi, M Matsumoto, Geriatrics Research Institute and Hp., 271; T Suyama, R Ubagai, Tominaga Hp., 261; H Itokawa, T Okazaki, M Fujimoto, M Moriya, S Kubota, N Okamoto, Kasai Shoikai Hp., 258; D Sato, T Sasaki, H Nagashima, Aizawa Hp., 254; T Hashimoto, T Nomura, Kushiro City General Hp., 250; K Kanemaru, T Yagishita, K Hashimoto, Yamanashi Univ., 250; H Ohta, I Ikushima, Miyakonojo Medical Association Hp., 237; S Miyachi, F Isaka, T Kuroiwa, M Yamada, H Oonishi, Y Uamada, Nishinomiya Kyoritsu Neurosurgical Hp., 232; H Ozawa, A Kurata, M Sasaki, Shiota General Hp., 226; Y Koguchi, T Yamauchi, K Masuda, M Tanaka, S Kobayashi, E Kobayashi, K Suzuki, Chiba Emergency Medical Center, 226; T Kuroiwa, H Oonishi, R Hiramatsu, Osaka Medical College, 219; D Shoda, N Tamakawa, M Tomokiyo, S Manabe, J Moroi, S Yoshioka, Y Matsumoto, Research Institute for Brain and Blood Vessels-Akita, 219; H Kitajima, Toki General Hp, 214; H Tenjin, M Nanto, Y Osaka, Japanese Redcorss Kyoto Daini Hp., 203; T Ishikawa, T Higa, Tokyo Women's Medical Univ., 198; T Akiyama, Y Niimi, S Onozuka, M Katayama, H Kagami, T Akiyama, Keio Univ., 191; S Iwabuchi, M Hayashi, T Yokouchi, N Yamana, Toho Univ. Ohashi Hp.,185; T Fujinaka, S Toyota, N Ohara, R Kajikawa, H Nakamura, T Nishida, Osaka Neurosurgical Hp., 184; O iIto, S Yamaguchi, Shinkoga Hp., 179; M Mase, N Hashimoto, T Ohno, M Oomura, K Demura, K Yamada, Nagoya City East Medical Center, 176;
S Ushikoshi, M Miyamoto, Hokkaido Medical Center, 174; S Yamaguchi, O Ito, K Uda, K Yasumori, Hamanomachi Hp., 173; Y Ueno,Y Kuramoto, N Shinoda, H Imamura, S Tateshima, H Adachi, C Sakai, N Sakai, Shinko Hp., 173; J Momoji, Naha City Hp., 170; N Shimamura, Hirosaki Univ., 169; K Owada, Y Inoue, Kyoto Prefectural Univ. of Medicine, 168; K Ebihara, I Nakahara, H Oishi, M Hayasaka, Kimitsu Chuo Hp., 165; H Matsumoto, H Takemoto, Y Hirohata, Kishiwada Tokushukai Hp., 164; I Naito, S Furuichi, K Asakura, H Shimaguchi, K Wakabayashi, K Sato, Japanese Redcross Maebashi Hp., 162; M Sakamoto, H Takeuchi, T Uno, Tottori Univ., 156; M Mase, N Aihara, Y Nishikawa, Nagoya City Univ. Hp., 150; Y Akiyama, E Ogino, Tenri Hp., 146; Y Mitsuhashi, A Nishio, T Kawakami, K Hayasaki, S Yamauchi, Osaka City Univ. Hp., 141; T Takahashi, M Ezura, Y Matsumoto, Japanese Redcross Saitama Hp., 140; H Morishima, K Ooshima, H Ito, Kawasaki Municipal Tama Hp., 131; M Maekawa, Mejiro Hp., 130; K Harada, J Morioka, S Watanabe, Y Sakata, Fukuoka Shin Mizumaki Hp., 124; M Ohashi, Soseikai General Hp., 124; N Hayashi, M Kawanishi, A Shindo, T Yano, Osaka Neurosurgical Hp., 122; A Ogata, Y Takase, Saga Univ., 121; T Takada, Y Otsuka, T Ueda, S Nogoshi, H Takeuchi, H Arakawa, St. Marianna Univ. School of Medicine Toyoko Hp., 117; T Sugawara, N Kimura, Iwate Prefectural Central Hp., 114; S Ozaki, T Ichikawa, Japanese Redcross Fukushima Hp., 113; T Okamoto, Japanese Redcross Nagoya Daiichi Hp., 113; T Munemitsu, M Saiki, Y Ueba, Shiga medical Center for Adults, 110; Y Yoshida, S Kominami, M Suzuki, A Watanabe, Ebara Hp., 108; O Kikuchi, H Wada, J Sakurai, Tomakomai Nisshou Hp., 105; H Wada, Asahikawa Medical Univ., 105; H Takata, S Shiraga, Kanazawa Medical Univ., 102; T Terada, H Morishima, S Koyama, D Wakui, H Onodera, K Ooshima, H Ito, St. Marianna Medical Univ Seibu Hp.,102; A Tsuji, T Tanaka, K Higuchi, K Uchida, M Shirakawa, K Maeno, Y Tanaka, A Kojima, M Katayama, S Kominami, M Suzuki, A Watanabe, K Srivatanakul, S Tanoue, M Okahara, J Kashiwagi, H Kiyosue, Y Hori, Y Sagara, R Shimada, T Yoshioka, T Higashi, Y Sambongi, M Negoro, A Miyasaki, O Hamasaki, Y Takabatake, S Kawada, A Handa, K Higuchi, H Fukuda, K Hamada, F Asakura, T Ichihashi, S Fukazawa, Y Nonaka, O Ito, M Shojima, K Akaji, T Kato, Y Kaku, F Isaka, S Kominami, H Sakai, K Fukui, J Kokuzawa, Y Egashira, H Minamide, T Suyama, T Hatano, J Kobayashi, N Ohara, T Higa, N Takeda, S Ota, M Arai, A Uemura, N Fukui, N Fujimura, Y Fukushima, N Uchiyama, M Mohri, R Higashi, Y Hirota, K Misaki, H Hiramatsu, Y Sugiura, K Watanabe, S Yamazaki, A Ishii, $\mathrm{T}$ Munemitsu, $\mathrm{M}$ Ando, $\mathrm{N}$ Murai, $\mathrm{T}$ Kikuchi, 
A Miyakoshi, Y Yamao, F Asakura, Y Yoshida, I Yamaura, H Minami, H Matsumoto, A Masuda, Y Hara, K Iihara, Y Suyama, H Yamasaki, Y Ishii, S Wakabayashi, S Tanoue, T Kubo, M Tsutsumi, A Shimada, Y Oura, A Fujita, A Kimoto, H Abe, H Takemoto, H Okada, R Yoshimura, Y Iwamuro, Y Obata, Y Yoshino, Y Kawano, K Matsumoto, T Mutoh, M Dehara, T Kubota, Y Inoue, K Kawarabuki, M Shirato, T Asano, Y Sagara, T Shibuya, T Suma, K Amari, H Oishi, M Yamamoto, S Iihoshi, K Miyata, K Fukasaku, R Tamaki, M Nishio, T Kojima, H Maekawa, M Yanaka, N Fukui, M Okawa, M Iwaasa, T Higashi, M Goda, T Kubo, M Hirai, M Yamada, M Kawanishi, Y Yoshino, S Nemoto, N Kuwayama, H Yamamoto, N Akioka, H Nakayama, K Nakabayashi, S Koyama.

\section{References}

1) Sakai N, Yoshimura S, Taki W, et al.: Recent trends in neuroendovascular therapy in Japan: analysis of a nationwide survey-Japanese Registry of Neuroendovascular Therapy (JR-NET) 1 and 2. Neurol Med Chir (Tokyo) 54: 1-8, 2014

2) Berkhemer OA, Fransen PS, Beumer D, et al.: A randomized trial of intraarterial treatment for acute ischemic stroke. N Engl J Med 372: 11-20, 2015

3) Campbell BC, Mitchell PJ, Kleinig TJ, et al.: Endovascular therapy for ischemic stroke with perfusionimaging selection. N Engl J Med 372: 1009-1018, 2015

4) Goyal M, Demchuk AM, Menon BK, et al.: Randomized assessment of rapid endovascular treatment of ischemic stroke. N Engl J Med 372: 1019-1030, 2015

5) Jovin TG, Chamorro A, Cobo E, et al.: Thrombectomy within 8 hours after symptom onset in ischemic stroke. N Engl J Med 372: 2296-2306, 2015

6) Saver JL, Goyal M, Bonafe A, et al.: Stent-retriever thrombectomy after intravenous t-PA vs. t-PA alone in stroke. N Engl J Med 372: 2285-2295, 2015

7) Jabbour P, Chalouhi N, Tjoumakaris $S$, et al.: The Pipeline Embolization Device: learning curve and predictors of complications and aneurysm obliteration. Neurosurgery 73: 113-120, 2013

8) van Swieten JC, Koudstaal PJ, Visser MC, Schouten $\mathrm{HJ}$, van Gijn J: Interobserver agreement for the assessment of handicap in stroke patients. Stroke 19: 604-607, 1988

9) Smith WS, Sung G, Starkman S, et al.: Safety and efficacy of mechanical embolectomy in acute ischemic stroke: results of the MERCI trial. Stroke 36: 1432-1438, 2005
10) Smith WS, Sung G, Saver J, et al.: Mechanical thrombectomy for acute ischemic stroke: final results of the Multi MERCI trial. Stroke 39: 1205-1212, 2008

11) Higashida RT, Halbach VV, Dowd CF, Juravsky L, Meagher S: Initial clinical experience with a new self-expanding nitinol stent for the treatment of intracranial cerebral aneurysms: the cordis enterprise stent. AJNR Am J Neuroradiol 26: 1751-1756, 2005

12) Henkes H, Bose A, Felber S, et al.: Endovascular coil occlusion of intracranial aneurysms assisted by a novel self-expandable nitinol microstent (neuroform). Interv Neuroradiol 8: 107-119, 2002

13) Bose A, Hartmann M, Henkes $H$, et al.: A novel, self-expanding, nitinol stent in medically refractory intracranial atherosclerotic stenoses: the Wingspan study. Stroke 38: 1531-1537, 2007

14) Penumbra Pivotal Stroke Trial Investigators: The penumbra pivotal stroke trial: safety and effectiveness of a new generation of mechanical devices for clot removal in intracranial large vessel occlusive disease. Stroke 40: 2761-2768, 2009

15) Saver JL, Jahan R, Levy EI, et al.: Solitaire flow restoration device versus the Merci retriever in patients with acute ischaemic stroke (SWIFT): a randomised, parallel-group, non-inferiority trial. Lancet 380: 1241-1249, 2012

16) Nogueira RG, Lutsep HL, Gupta R, et al: Trevo versus Merci retrievers for thrombectomy revascularisation of large vessel occlusions in acute ischaemic stroke (TREVO 2): a randomised trial. Lancet 380: 1231-1240, 2012

17) Yoshimura S, Sakai N, Uchida K, et al.: Endovascular therapy in ischemic stroke with acute largevessel occlusion: recovery by endovascular salvage for cerebral ultra-acute embolism Japan registry 2 . J Am Heart Assoc 7: pii: e008796, 2018

18) Chen JH, Huang CY, Lee YC, et al.: Comparative cost analysis for the surgical and endovascular treatment of ruptured intracranial aneurysms in Taiwan: a nationwide population-based cohort study. World Neurosurg 116: e485-e490, 2018

19) Massop D, Dave R, Metzger C, et al.: Stenting and angioplasty with protection in patients at high-risk for endarterectomy: SAPPHIRE Worldwide Registry first 2,001 patients. Catheter Cardiovasc Interv 73: 129-136, 2009

Address reprint requests to: Nobuyuki Sakai, MD, DMSc, Department of Neurosurgery, Kobe City Medical Center General Hospital, 2-1-1 Minatojima Minaminachi Chuo, Kobe, Hyogo 650-0047, Japan.

e-mail:n.sakai@siren.ocn.ne.jp 